\title{
Capturing Nordic Identifications Through Participatory Photography
}

\section{Corner, Solveig}

Springer

2019

Corner , S , Forsius , M , Holm , G , Zilliacus , H \& Öhrn , E 2019 , Capturing Nordic Identifications Through Participatory Photography . in A P Costa , L P Reis \& A Moreira (eds) , COMPUTER SUPPORTED QUALITATIVE RESEARCH: NEW TRENDS ON QUALITATIVE RESEARCH : New Trends on Qualitative Research. Advances in Intelligent Systems and Computing , no. 861, Springer , Cham , pp. 136 - 145, WCQR 2018 3rd World Conference of Qualitative Research , Lisbon , Portugal , 17/10/2018 . https://doi.org/10.1007/978-3-030-01406-3_12

http://hdl.handle.net/10138/308661

https://doi.org/10.1007/978-3-030-01406-3_12

acceptedVersion

Downloaded from Helda, University of Helsinki institutional repository.

This is an electronic reprint of the original article.

This reprint may differ from the original in pagination and typographic detail.

Please cite the original version. 
Note. This is the final version of the submitted manuscript.

Please cite as: Cornér, S., Forsius, M., Holm, G., Zilliacus, H., \& Öhrn, E. (2018).

Capturing Nordic Identifications through Participatory Photography. WCQR2018.

3 rd World Conference on Qualitative Research 2018. 17-19.10.2018, Lissabon, Portugal.

\title{
Capturing Nordic Identifications through Participatory Photography
}

\author{
Solveig Cornér, ${ }^{1}$ Maria Forsius, ${ }^{1}$ Gunilla Holm, ${ }^{1}$ \\ Harriet Zilliacus, ${ }^{1}$ and Elisabet Öhrn ${ }^{2}$ \\ ${ }^{1}$ Faculty of Education, University of Helsinki, Finland \\ ${ }^{2}$ Department of Education and Special Education, University of Gothenburg, \\ Sweden
}

\begin{abstract}
This study explores how participatory photography can be used in researching upper secondary students' identifications with what it means to live in one of four Nordic countries. The study draws on students' constructions and interpretations of photographs. For this article the data analyzed consisted of 571 photographs taken during spring 2018 by a total of 104 students in the metropolitan areas in Helsinki, Stockholm, Oslo and Copenhagen. The analysis of the photographs and their captions show that students associated themselves mostly in a positive way with the Nordic region, though also some critical attitudes were identified. Visual ethnography in education as a method enhanced the upper secondary students' way of giving meaning to what living in the Nordic countries means to them. Moreover, the method enables the students to become co-researchers together with the research team in both an aesthetic and narrative way. The study offers insights into how participatory photography can be as a useful and activating method in both local and cross-national research.
\end{abstract}

Keywords: Participatory photography, identification, upper secondary students, Nordic region 


\section{Introduction}

Photography as a research method in qualitative research is growing and evokes a lot of interest. It is argued that children and young people are seldom heard in the school environment and therefore photographs offer possibilities for young peoples' engagement in research (Lodge, 2009). In addition, Lodge (2009) points out, that photography as a method is especially useful in the engagement of marginalized and shy students in school.

Our study is conducted in four countries in the Nordic region. The Nordic countries are geographically and culturally close and often referred to as the Nordic region. The Nordic region consists of Finland, Sweden, Norway, Denmark and Iceland, as well as Greenland, the Faroe Islands and the Alland islands. Education has been vital to the development of the Nordic welfare model and might even, as Antikainen (2006) suggests, be seen as one of its main preconditions. The educational systems in the Nordic countries emphasize the equality of opportunity for all of its citizens (Isopahkala-Bouret \& al., 2018). According to a recent study conducted by the Nordic council of ministers (Andreasson \& Stende, 2017), collaboration in different areas between the Nordic countries is highly valued by the Nordic citizens. However, considering the seemingly high interest in the shared opportunities by the Nordic citizens, we know surprisingly little about how young people experience the meaning of living in a country belonging to the Nordic region. Given the importance of future Nordic societal development and collaboration, there is a need to better understand the perspectives of young people and what shared perceptions in the Nordic region means to them. At the moment, the research literature on what the Nordic is from young peoples' perspective, is scarce.

The overall study focused on how young people in Finland, Sweden, Denmark and Norway perceive what it means to live in a Nordic country and what being Nordic means. The study was conducted through participatory photography and by this, our aim was to produce both robust information on the foci and different kinds of understanding and information (Pink, 2012; Rose, 2016). We draw on a recent empirical study from four Nordic countries to analyze this, and also on the authors' previous work related to the topics and empirical work on gender, class and ethnicity in urban schools (Öhrn, 2009, 2011, 2012; Öhrn \& Weiner, 2017) and justice through education, bilingual school space, intercultural education, arts-based visual research and ethnographic analyses (Holm, 2014, 2018; Holm, Londen \& Mansikka, 2015; Holm, Sahlström \& Zilliacus, 2018). The focus of this paper is though specifically on how participatory photography can be used in exploring young people's identifications with, in this case, the Nordic.

\section{What does it mean to be Nordic?}

Youth identifications with the Nordic is seen in this study as being citizens in one of the Nordic countries from their perspective e.g. what it means to be "Nordic". Rather than seeing identifications as fixed, the term "identification", more strongly than 
"identity", expresses a process, which includes relating to other individuals, communities, situations or categories within a particular context. From a non-essential view, identifications are perceived as fluid and changing tied to specific cultures rather than being fixed and stable (Anthias, 2011; Hall, 1996).

The identifications of youth today reflect the increasingly globalising and postmodern society, which is under constant and rapid change. Youth form their identities in the context of multiple traditions through a mix of local and global traditions, via both first hand and virtual media reality, which transcend the borders of nations and separate 'cultures' (Verschueren, 2008). There is today more space to negotiate and chose our identities. However, there are notably also inequalities in the distribution of opportunities among youth (Gewirtz \& Crib, 2008). Identifications include a number of different aspects, such as, gender, home culture, country or dominant culture, ethnicity or appearance, religion, language, sexuality, subcultures/hobbies, profession, and social class. Included are also individual qualities, which can for instance refer to individual abilities or disabilities. These different identifications intersect, that is, the different aspects inter-relate and crosscut within people's lives and in social relations (Anthias, 2011).

Identifications are closely connected with a sense of belonging as they express membership in a social group, community or nationhood. They can create forms of solidarity bringing people and groups together. Students' identities are importantly developed within the context of the school and with peers. The process of identification, necessarily also involves construction of boundaries and exclusion, separating ourselves from what we are not (Anthias 2011). The school is a primary arena for dealing with a whole array of differences, and students construct their identifications as much through notions of how others see "us" and "who we are not" as through conceptions of who "we" are (Reay 2009, 277-278). A complex view of identifications is reflected onto the view of citizenship, and that youth today have plural and diverse citizenships. The national level and the nation state are still relevant levels, but globalization challenges static and one-dimensional models of citizenships with new transnational levels such as the Nordic, the global or the cosmopolitan. Classic civic belonging is substantially and continually being transformed in the landscape of social media, consumerism, and popular culture. Therefore, diverse forms of belonging and citizenship, which transcend national boarders, need to be considered when studying youth (Banks, 2008; Hoikkala, 2009; Mansikka \& Holm, 2011).

\section{Aim}

The aim of this study is to explore how upper secondary students in the Nordic capitals identify themselves with the Nordic region by using participatory photography. The following research question was addressed: How can participatory photography as a research method be used to study upper secondary school students' identifications with the Nordic and the Nordic region? What does it mean to them to live in a Nordic country? 


\section{The Study}

The principal aim of this study was to investigate and understand how participatory photography can be used to study upper secondary students' identifications with the Nordic and the Nordic region. As Holm (2018) states, "participatory photography means that the research participants take the photographs, and in this way become a kind of co-researchers/co-ethnographers". While the participants take the photos and are engaged from the beginning of the project, it enables the researchers to get a sense of what the participants want to show as important or interesting from their own worlds (Holm, 2018). Further, participatory photography can be described as a way to study identities and identifications, since it allows the participants, in our case upper secondary students, to control how they portray their perceptions of who they are (Holm, Londen \& Mansikka, 2015).

The data consist of 571 photographs taken in spring 2018 and are read in the context of the upper secondary students' urban environment, with decent housing, good facilities for cultural and leisure activities, but also visible segregation, conflicts and inequalities (Öhrn \& Winer, 2017). A total of 104 upper secondary students from four upper secondary schools in metropolitan Helsinki $(n=17)$, Stockholm $(n=24)$, Oslo $(n=30)$, and Copenhagen $(n=33)$ participated in the study. The research team collectively decided what schools would be invited to participate in the project based on their location in the capital regions. In the second stage, the principals of each school were contacted by one of the researchers and the principal explored the teachers' interest in participating in the research. The upper secondary schools varied from each other. However, the student population is well represented in terms of age and area, since the mean age in each country was nearly the same and the schools were all located in the urban metropolitan areas in each country. A majority ( $\mathrm{f}=63 / 60.5 \%$ ) of the participants were female. Some schools were more culturally diverse than others. The demographics of the participants and the number of photographs are shown in Table 1 .

Table 1. Demographics (gender and age) for participants in Finland, Sweden, Norway and Denmark, number of photographs

\begin{tabular}{llllc}
\hline Country & $\begin{array}{l}\text { Participants } \\
\mathrm{f} /(\%)\end{array}$ & $\begin{array}{l}\text { Gender } \\
\mathrm{m} / \mathrm{f}\end{array}$ & $\begin{array}{l}\text { Age } \\
\text { (mean) }\end{array}$ & $\begin{array}{l}\text { Photographs } \\
\text { taken/country }\end{array}$ \\
\hline Finland & $17(16)$ & $1 / 16$ & 17 & 65 \\
Sweden & $24(23)$ & $13 / 11$ & 18 & 132 \\
Norway & $30(29)$ & $10 / 20$ & 17 & 133 \\
Demark & $33(31)$ & $17 / 16$ & 16.5 & 241 \\
Total & $104(100)$ & $41 / 63$ & 17 & 571 \\
\hline
\end{tabular}

The data were collected, by two of the researchers in the four countries between February and May 2018. The students were asked to photograph, with their mobile phones, themes that they associated with the Nordic region and that in some way captured how they experienced living in a Nordic country. In order to make the photographs more understandable to the viewer, the students were asked to write a short 
caption to every photo. Students could take as many photographs as they liked but could upload only the ten best photographs per student in order to keep the number of photographs manageable. The photographs were then uploaded to a shared projectplattform. Prior to conducting their task, the students were introduced to the aim of the project and additionally took part in a brainstorming session about the Nordic region, where the Nordic was further discussed. The students had 1-3 weeks to do photographs depending on the schools' schedules. All students participating in the project gave their written consent.

\subsection{Analysis}

The analysis started with a careful overview of the photographs (Keats, 2009). When analyzing the photographs, the captions helped the researchers to interpret the students' photographs as intended by the students (Holm, Londen \& Mansikka, 2015). This was especially crucial when interpreting photographs that were more symbolic or metaphorical. The research team categorized the students' photographs according to the emerging themes, but also into informative photographs and symbolic photographs (Holm, Londen \& Mansikka, 2015; Elliot, Reid \& Baumfield, 2017). A preliminary descriptive coding into a theme was made during the first phase of analyzing the photographs. The decision of coding a certain photograph as a theme was made when the photograph captured something important about the data associated to the research question (Braun \& Clarke, 2006; Rose, 2016). The main themes identified in the analysis process of the photographs were belonging to the welfare state, youth culture, individualism versus collectivism, the Nordic nature, Nordic traditions, architecture, healthy living, and technology. Three of the authors conducted the analysis process as a team. The authors conducted the categorization of the photographs into themes collectively.

\section{Results}

The preliminary results show that the students' reflected upon several themes in relation to their identification of the Nordic region in the photographs. The students perceived their privileges of living in the Nordic welfare states (such as free education, health care, social security as well as safety and equality) as one of the most important themes. The youth culture was another theme frequently portrayed and discussed. Other common Nordic themes were youth culture in relation to alcohol, and in contrast, healthy living (healthy food, sport, outdoor activities). The students also associated the frequent use of technology and social media in everyday life as a way of being a Nordic citizen. The results illustrate further that students constructed both informative and symbolic photographs in relation to the various themes.

\subsection{Informative photographs}

As in Elliot et al. (2017), informative photographs tended to focus on situations that directly related to experiences significant for the students. For example, a frequent theme captured by the students in all Nordic countries, were their association with 
equality. The students pointed out in their pictures that, due to the Nordic welfare states, people have equal possibilities to live a good life and to choose the kind of life they want to live. They brought up equality in several ways: between genders, between adults and children and as equal rights for people with disabilities as well as for sexual minorities. As examples, a Norwegian student illustrated the rights for all people in the Nordic countries to get married (Figure 1) whereas a Danish student illustrated gender equality by capturing a man on parental leave (Figure 2). The students associated, in addition, the strong well-fare society with the opportunity for free education for everyone (Figure 3).

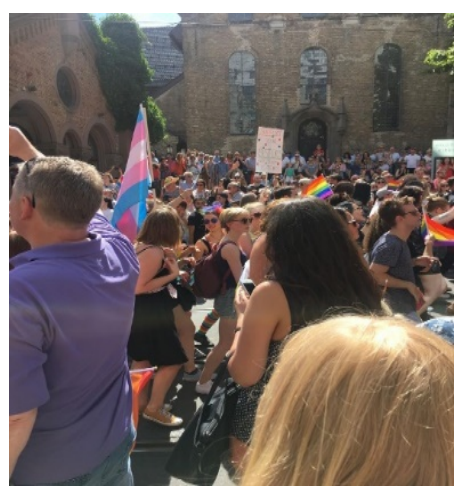

Figure 1. "Same-sex marriage is legal in all Nordic countries" (Norwegian student)

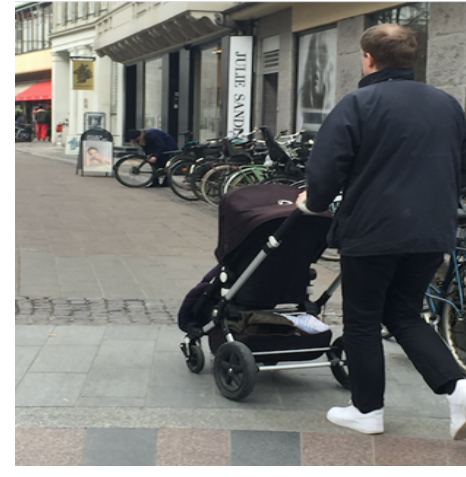

Figure 2: "Men use their right to parental leave, and take care of the children, more frequently than in other countries" (Danish student)

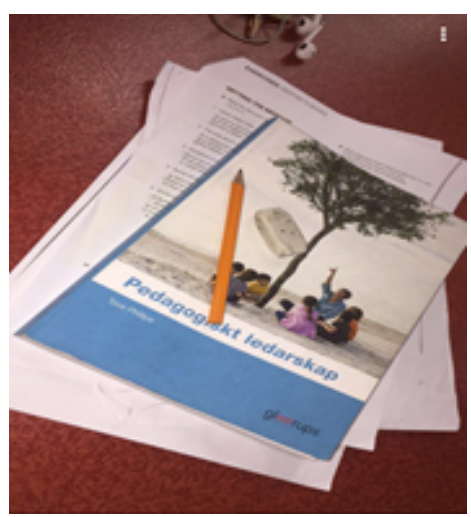

Figure 3: "Children in the Nordic countries are entitled to free education and books" (Swedish student) 
Further, in connection to the youth culture, the students frequently chose to illustrate the active life that is typical for the Nordic region, since, for example, bicycling and skiing (Figures 4 and 5) are common activities among the youth.

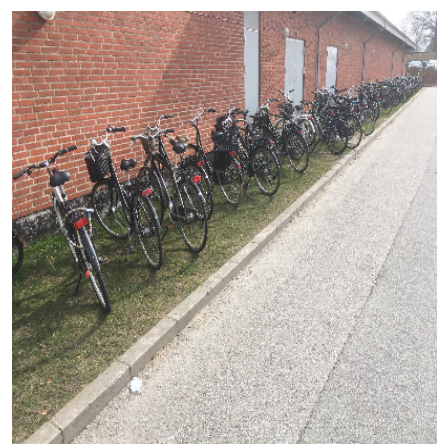

Figure 4: "It's Nordic to bike and think about the environment" (Danish student)

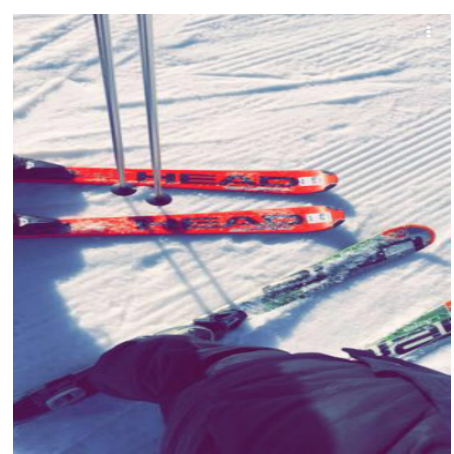

Figure 5: "Skiing is a Nordic tradition" (Swedish student)

The students' also systematically showed their appreciation for the four seasons and the beautiful nature in the Nordic countries (figure 6). However, in opposite to the emphasis on healthy living, the students shared many photographs describing a youth culture associated with heavy alcohol use (Figure 7).

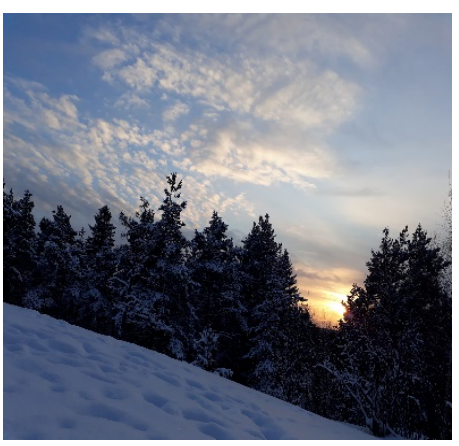

Figure 6: "Our nature is unique and wonderful - especially in wintertime" (Finnish student)

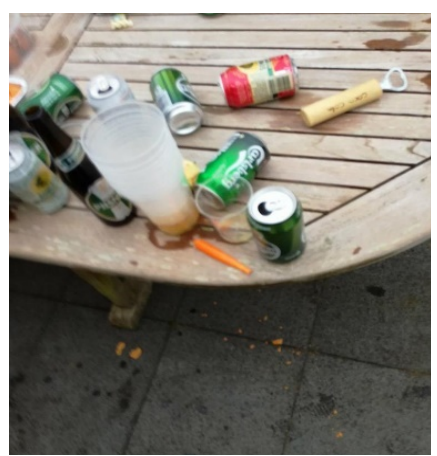

Figure 7: "To party is a part of life" (Danish student)

\subsection{Symbolic photographs}

Symbolic photographs are more complex and more difficult to interpret without understanding the photographers' habitus and the context (Holm et al., 2015). However, 
in most cases they also deal with deeper, more serious issues that might be difficult for the students to express in words. A Finnish student captured, for instance, the Nordic welfare state as feeling safe in the Nordic countries in a symbolic photograph (Figure 8), accompanied by a describing caption. A Swedish student additionally illustrated the perception that there is an individualistic culture in the Nordic countries with a photograph of a drawing where all the focus is on the individual (Figure 9). The meaning of these symbolic photographs and other similar ones would be difficult to understand without the captions (Holm, Londen \& Mansikka, 2015).

Students' perceptions of the possibilities and opportunities living in a Nordic country were often quite idealistic and uncritical. For example, students emphasized gender equality, which is better than in most other countries but by no means perfect. However, some critical reflections were brought forth by several students through photographs about, for example, the alcohol centered youth culture.

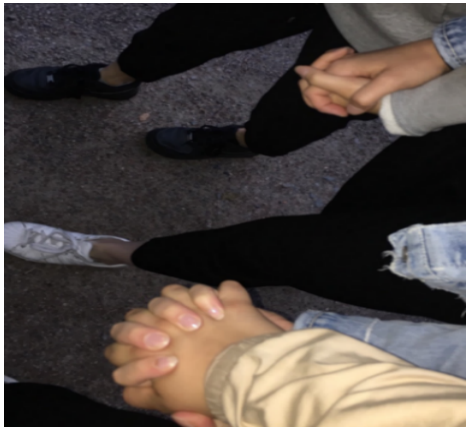

Figure 8: "I feel safe living in Finland. It is possible to walk alone on the street and express your opinion without having to be afraid." (Finnish student)

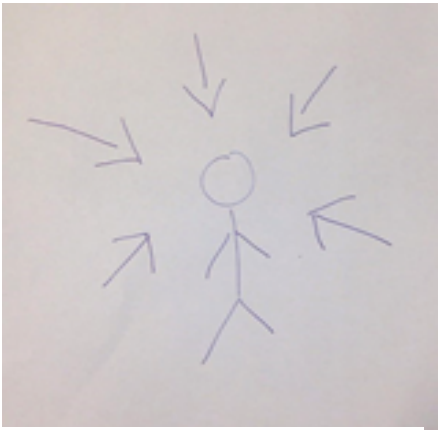

Figure 9: We have an individualistic culture in the Nordic countries" (Norwegian student)

\section{Conclusion}

This study focused on how young people through participatory photography can show what living in the Nordic countries means to them. The method worked well when exploring different aspects of the students' identifications with what it means to live in a Nordic country. In line with Holm (2018), the method enables the students to become co-researchers together with the research team in both an aesthetic and narrative way, since the students were in charge of constructing their photographs. Students had to reflect on their own lives and the societies they live in as well as the neighboring countries in order to photograph their thoughts. Further, consistent with Holm (2018), using participatory photography with captions enabled the participants to bring forth the reason why they have taken a photograph and what they want to emphasize. The captions pushed students to compose thoughtful photographs in order 
for the photographs to have an understandable meaning. In summary, this study brings forth insights into how participatory photography can serve as a useful and activating method with young people in both local and cross- national educational research.

Acknowledgements. This research was supported by the Nordic Centre of Excellence 'Justice through Education' financed by NordForsk grant \# 57741.

\section{References}

Andreasson, U. \& Stende, T. (2017) Ett värdefullt samarbete: Den nordiska befolkningens syn på Norden. A valuable co-operation: The view of the Nordic cooperation by the Nordic people. Nordic Council of Ministers. Retrieved 04.12.2017 from http://norden.divaportal.org/smash/record.jsf?pid=diva2\%3A1152251\&dswid=-2647

Anthias, F. (2011). "Intersections and Translocations: New Paradigms for Thinking about Cultural Diversity and Social Identities." European Educational Research Journal 10 (2): 204-216.

Antikainen, A. (2006). In search of the Nordic model in education. Scandinavian Journal of Educational Research, 50(3), 229-243.

Banks, J. A. (2008). Diversity, Group Identity, and Citizenship Education in a Global Age. Educational Researcher, Vol 37, Issue 3, pp. 129-13, https://doi.org/10.3102/0013189X08317501

Braun, V. \& Clarke, V. Using thematic analysis in Psychology. Qualitative Research in Psychology, 3:2, 77-101 (2006)

Elliot, D. L., Reid, K. \& Baumfield, V. (2017). Capturing visual metaphors and tales: innovative or elusive? International Journal of Research \& method in Education, 40:5, 480-496, DOI: 10.1080/1743727x.2016.1181164

Gewirtz, S. \& A. Cribb. (2008). "Taking Identity Seriously: Dilemmas for Education Policy and Practice.” European Educational Research Journal 7 (1): 39-49.

Hall, S. (1996). “Who Needs 'Identity'?” In Questions of Cultural Identity, edited by S. Hall and P. Gay, 1-17. London: Sage Publications.

Holm, G. (2014). Photography as a research method. Leavy, P. (eds., In The Oxford Handbook of Qualitative Research. New York: Oxford University Press.

Holm. G., Londen, M. \& Mansikka, J-E. (2015). Interpreting Visual (and Verbal) Data: Teenagers' Views on Belonging to a Language Minority Group. In Smeyers, P., Bridges, D., Burbules, N. C. \& Griffiths, M. (eds.), International Handbook of Interpretation in Educational Research: Part One. Dordrecht: Springer.

Holm, G. (2018). Visual ethnography in Education. In D. Beach, C. Bagley \& S. Marquez da Silva (Eds.). The Wiley Handbook of Ethnography of Education. Wiley Blackwell.

Holm, G., Sahlström, F. \& Zilliacus, H. (2018). Arts-Based Visual Research. In Leavy, P. (eds.), Handbook of arts-based research. (pp. 311-335). New York: Guilford Press.

Hoikkala, T. (2009). The diversity of youth citizenships in the European Union. Nordic Journal of Youth Research Vol 17(1): 5-24 https://doi.org/10.1177\%2F110330880801700102 
Isopahkala-Bouret, U., Börjesson, M., Beach, D., Haltia, N., Jónasson, J.T., Jauhiainen, A., Jauhiainen, A., Kosunen, S., Nori, H., \& Vabø, A. (2018). Access and stratification in Nordic higher education. A review of cross-cutting research. $E d u$ cation Inquiry, 9(1), 142-154. doi: 10.1080/20004508.2018.1429769

Keats, P.A. (2009). Multiple text analysis in narrative research. Visual, written, and, spoken stories of experience. Qualitative research 9: 181-195.

Lodge, C. (2009). About face: Visual research involving children. Education; 37(4): $3-13$.

Mansikka, J.- E. \& Holm, G. (2011). On reflexivity and suspension: perspectives on a cosmopolitan attitude in education. Nordic Studies in Education, Vol. 31, pp. $76-85$.

Verschueren, J. (2008) Intercultural Communication and the Challenges of Migration, Language and Intercultural Communication, 8:1, 21-35, DOI: 10.2167/laic298.0

Pink, S. (2012). Doing Visual Ethnography. London: SAGE.

Reay, D. (2009). "Identity Making in the Classrooms." In The Sage Handbook of Identities, edited by M. Wetherell and C.T. Mohanty, 277-294. London: Sage.

Rose, G. (2016). Visual Methodologies. London: Sage.

Öhrn, E. (2009). Challenging sexism? Gender and ethnicity in the secondary school, Scandinavian Journal of Educational Research, 53(6), 579-590.

Öhrn, E. (2011). Class and ethnicity at work. Segregation and conflict in a Swedish secondary school. Education Inquiry, 2(2), 345-355.

Öhrn, E. (2012). Urban education and segregation: the responses from young people, European Educational Research Journal, 11(1), 45-57.

Öhrn, E. \& Weiner, G. (2017). Urban education in the Nordic countries: Section editors' introduction. In W. Pink \& G. Noblit (Eds), Second international handbook of urban education (p 649-669). Switzerland: Springer. 